\title{
Demographic factors associated with the diet quality of older US men: baseline data from the Osteoporotic Fractures in Men (MrOS) study
}

\author{
J Shannon ${ }^{1, *}$, JM Shikany ${ }^{2}$, E Barrett-Connor ${ }^{3}$, LM Marshall ${ }^{1}, \mathrm{CH}$ Bunker ${ }^{4}, \mathrm{JM}$ Chan ${ }^{5}$, \\ $\mathrm{KL}$ Stone ${ }^{6}$ and $\mathrm{E}$ Orwoll ' for the Osteoporotic Fractures in Men (MrOS) Research Group \\ 'Oregon Health \& Science University, Portland, OR, USA: ${ }^{2}$ University of Alabama at Birmingham, Birmingham, AL, \\ USA: ${ }^{3}$ University of California, San Diego, CA, USA: ${ }^{4}$ University of Pittsburgh, Pittsburgh, PA, USA: ${ }^{5}$ University of \\ California, San Francisco, CA, USA: ${ }^{6}$ San Francisco Coordinating Center, California Pacific Medical Center- \\ Research Institute, San Francisco, CA, USA
}

Submitted 10 May 2006: Accepted 18 September 2006: First published online 6 March 2007

\begin{abstract}
Objective: Throughout the world, the proportion of the male population aged 65 years and older is increasing. Yet, we have limited information regarding diet quality and predictors of diet quality in this segment of the population. The objectives of the current analyses are to describe the diet quality of a cohort of men $>65$ years of age, and identify lifestyle factors associated with poor diet quality.

Methods: We present a cross-sectional analysis of the diet quality of 5928 men, aged 65-100 years, who are participants in the Osteoporotic Fractures in Men (MrOS) cohort study. Dietary intake was determined using a modified Block 98 foodfrequency questionnaire. Diet quality was calculated using the previously validated Diet Quality Index-Revised (DQI-R). Univariate and multivariate modelling was used to estimate the variance in diet quality predicted by a number of sociodemographic factors, including age, race/ethnicity, body mass index (BMI), marital status, education, smoking status, physical activity, self-perceived health and nutritional supplement use.

Results: Overall, we found that in this geographically diverse group of older men, diet quality was low, with a mean modified DQI-R for the entire study population of 62.5 (standard deviation 13.1) out of an ideal of 100. Further, younger age, very low total calorie intake $\left(\leq 1187 \mathrm{kcal} \mathrm{day}^{-1}\right)$, higher BMI, residence in a North or Southeast community, being of African-American or Hispanic race, being less educated, not using dietary supplements and smoking were each significant independent predictors of a poorer diet.

Conclusion: These data may prove useful in both understanding the dietary intake of older US men as it relates to published dietary guidelines, and for targeting future dietary intervention programmes.
\end{abstract}

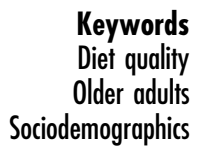

As the population in the USA continues to age, the health and well-being of the elderly is becoming a large social and economic concern. Diet is a key component in the prevention and treatment of multiple chronic diseases including heart disease, diabetes, cancer and osteoporosis (http://fnic.nal.usda.gov/nal_display/index.php?info_center $=4 \&$ tax_level $=1 \&$ tax_subject $=278$ ). Currently, our understanding of the diets of older US men comes primarily from nationwide surveys such as NHANES (National Health and Nutrition Examination Survey) and a limited number of smaller, population-based studies ${ }^{1-5}$. While there has been some work describing dietary patterns among older men ${ }^{6-10}$, there is little published work describing demographic or social factors that may predict dietary patterns.
In a recent study of older adults (aged 55-74 years) in Quebec, Shatenstein et al. reported that approximately half of the 460 men and women interviewed showed inadequate diet diversity and consumed less than the recommended servings of specified foods, including grain products, fruit and vegetables, milk products and meats or meat alternatives ${ }^{11}$. In another study of 179 older, rural Pennsylvanians (107 men), being male was statistically significantly associated with falling into the 'low-nutrientdense' (defined as higher intakes of foods from the breads and fats, oils and sweets groups) dietary pattern cluster ${ }^{12}$. Haveman-Nies et al. evaluated diet quality in elderly Europeans and Americans, and reported that higher diet quality was related to non-smoking, less body fat and more physical activity ${ }^{10}$. Based on the limited research 
available, older men may be at increased risk of poor dietary intake, placing them at increased risk for chronic disease. We propose that an understanding of diet and factors that influence intake among a large, diverse group of older US men may help guide the need for targeted intervention programmes, and could provide a baseline assessment from which to determine future chronic disease risk potential based on dietary patterns. Here, we present our analyses of the diet quality of Osteoporotic Fractures in Men (MrOS) cohort participants aged $\geq 65$ years and evaluate how specific demographic characteristics may be associated with diet quality.

\section{Methods}

\section{Study participants}

The design and aims of the MrOS study have been described elsewhere ${ }^{13}$. Briefly, the MrOS cohort consists of 5995 community-dwelling, US men aged $\geq 65$ years recruited between March 2000 and April 2002. The goal of the study is to quantify risk factors for fracture among older men. Participants were recruited primarily through mass mailings in six geographic regions of the USA: Birmingham, AL; Minneapolis, MN; Palo Alto, CA; Pittsburgh, PA; Portland, OR; and San Diego, CA. Eligibility criteria were: (1) ability to walk without the assistance of another; (2) no history of bilateral hip replacement; (3) ability to provide self-reported data; (4) anticipated residence near a study site for the duration of follow-up; (5) absence of a medical condition that would result in imminent death; and (6) ability to understand and sign an informed consent. The Institutional Review Board at each recruitment site approved the study protocol, and written informed consent was obtained from all participants.

\section{Nutrition assessment}

We obtained information about the participants' typical diet using a self-administered, reduced length version of the Block 98 food-frequency questionnaire (FFQ). Participants were mailed the questionnaire to complete prior to their clinic visit. At the clinic visit, questionnaires were reviewed by clinic staff to ensure completeness. The reduced length version of the Block 98 semi-quantitative questionnaire used for this study was developed through an in-depth analysis of the NHANES III data to identify foods most commonly consumed by men of a similar age, geographic and racial distribution as those in the MrOS cohort. Specific attention was paid to capturing intake of nutrients of interest to the MrOS study questions, including calcium, vitamin D and other selected nutrients that may influence risk of osteoporosis or prostate cancer in US men. The questionnaire included 69 individual food item questions and 14 items assessing nutritional supplement use. An additional 13 questions about food preparation and low-fat foods were asked and used to refine nutrient calculations. This specific reduced length version of the
Block 98 FFQ did not undergo validation, though it is similar to other previously validated reduced length questionnaires produced by the Block group ${ }^{14}$. Individual nutrient intake was determined by the Block group using a database based on the USDA Database for Standard Reference for Version 12, and the 1994-1996 CSFII database. Algorithms for FFQ nutrient analyses are described in detail elsewhere (http://www. nutritionquest.com/B98_Dev.pdf). Food nutrient values were calculated separately from supplement nutrient values. Servings of food groups were calculated through creating groupings of all foods that contribute to approximately one serving (in gram weight) of a food group, using the 1992 Food Pyramid recommended serving sizes (e.g. cheeses $-42 \mathrm{~g}$ ). The total grams of food consumed as part of each group was determined and then divided by the gram weight of a single serving size for that group.

To assess overall diet quality, a Diet Quality Index (DQI) score was calculated based on work by Haines et al. ${ }^{15}$. The DQI was originally developed as a composite or combined measure of diet quality based on global dietary recommendations from the Committee on Diet and Health of the National Research Council Food and Nutrition Board. The DQI published in $1994^{16}$ was revised (DQI-R) in $1999^{15}$ to incorporate dietary recommendations from the US Department of Agriculture's 1992 Food Guide Pyramid, and the dietary reference intakes ${ }^{17}$. We further modified the DQI-R to incorporate the 2001 dietary reference intakes for iron ${ }^{18}$. Additional changes were made to the added-sugars component of the dietary moderation score. As shown in Table 1, the modified DQI$\mathrm{R}$ consists of 10 components, each contributing 10 points to an overall diet quality score ranging from 0 to 100 . The 10 components were selected by Haines et al. to represent the recommended fat composition of the diet (total fat, saturated fat and cholesterol); diet proportionality, e.g. the differences in consumption of fruits, vegetables and grains as compared with the 1992 Food Pyramid recommendations; diet moderation, e.g. limiting use of added fats, sodium and sugar; and diet diversity, e.g. consuming a range of foods within food categories ${ }^{15}$. In applying the DQI-R to the MrOS data, we attempted to mirror the published scale to the extent possible, with the exception of the source of the iron value and modifying the method for calculating sweets. See Haines et al. for a complete discussion of the DQI-R scoring procedures ${ }^{15}$.

The modified DQI-R score is calculated by summing the resulting scores from each of the 10 categories. The continuous categories (fruits, vegetables, grains, iron and calcium) allow for values to be $>100 \%$ if a person consumes more than the recommended intake. As with the original DQI-R, these individuals are considered as having met the recommended intake and for calculation purposes are considered to have a score of $100 \%$. 
Table 1 Modified Diet Quality Index-Revised (DQI-R) ${ }^{15}$

\begin{tabular}{|c|c|c|}
\hline Component & Score & Scoring criteria \\
\hline Total fat $\leq 30 \%$ energy intake & $0-10$ points & $\begin{array}{l}-\quad \leq 30 \%=10 \\
-\quad>30 \text { to } \leq 40 \%=5 \\
-\quad>40 \%=0\end{array}$ \\
\hline Saturated fat $\leq 10 \%$ energy intake & $0-10$ points & $\begin{array}{l}: \quad \leq 10 \%=10 \\
-\quad>10 \text { to } \leq 13 \%=5 \\
-\quad>13 \%=0\end{array}$ \\
\hline Dietary cholesterol $<300 \mathrm{mg}$ day $^{-1}$ & $0-10$ points & $\begin{array}{l}-\quad \leq 300 \mathrm{mg}=10 \\
-\quad>300 \text { to } \leq 400 \mathrm{mg}=5 \\
-\quad>400 \mathrm{mg}=0\end{array}$ \\
\hline Fruit intake per day* & $0-10$ points & $\begin{array}{l}\text { Continuous \% of recommended intake: } \\
\qquad \quad 2 \text { servings if } \leq 1600 \mathrm{kcal}(6.7 \mathrm{MJ}) \text { per day } \\
-\quad 3 \text { servings if }>1600 \mathrm{kcal}(6.7 \mathrm{MJ}) \text { per day }\end{array}$ \\
\hline Vegetable intake per day* & $0-10$ points & $\begin{array}{l}\text { Continuous \% of recommended intake: } \\
\qquad \quad 3 \text { servings if } \leq 1600 \mathrm{kcal}(6.7 \mathrm{MJ}) \text { per day } \\
-\quad 4 \text { servings if }>1600 \mathrm{kcal}(6.7 \mathrm{MJ}) \text { per day }\end{array}$ \\
\hline Whole grain intake per day* & $0-10$ points & $\begin{array}{l}\text { Continuous \% of recommended intake: } \\
-6 \text { servings if } \leq 1600 \mathrm{kcal}(6.7 \mathrm{MJ}) \text { per day } \\
-\quad 9 \text { servings if }>1600 \mathrm{kcal}(6.7 \mathrm{MJ}) \text { per day }\end{array}$ \\
\hline $\begin{array}{l}\text { Calcium intake as \% of DRI† } \\
\text { Iron intake as \% of DRIł }\end{array}$ & $\begin{array}{l}0-10 \text { points } \\
0-10 \text { points }\end{array}$ & $\begin{array}{l}\text { Continuous \% of recommended intake }\left(1200 \mathrm{mg} \mathrm{day}^{-1}\right) \\
\text { Continuous } \% \text { of recommended intake }\left(8 \mathrm{mg} \mathrm{day}^{-1}\right)\end{array}$ \\
\hline $\begin{array}{l}\text { Dietary diversity score (each representative food } \\
\text { must be consumed at least } 3-4 \text { times per week } \\
\text { to be included in the score) }\end{array}$ & $0-10$ points & $\begin{array}{l}\text { Sum of: } \\
\text { - grains (rolls, quickbreads, pasta, pizza/cracker, } \\
\text { cooked cereals, cold cereal, rice) } / 7 \times 2.5 \\
\text { vegetables (cabbage/salad/peas/other, white } \\
\text { potatoes, tomato/tomato juice, starchy veg/corn, } \\
\text { tofu/dry beans, carrot/sweet potato, } \\
\text { spinach/broccoli) } / 7 \times 2.5 \\
\text { fruits (banana/apple/other fruits } / 100 \% \text { fruit juices, citrus } \\
\text { fruits) } / 2 \times 2.5 \\
\text { - protein }(\text { red meat, milk, chicken, cheese, eggs, fish, } \\
\text { yoghurt) } / 7 \times 2.5\end{array}$ \\
\hline Dietary moderation score & $0-10$ points & $\begin{array}{l}\text { Sum of: } \\
\text { - } \text { sodium intake }\left(\mathrm{mg} \mathrm{day}^{-1}\right): \leq 2400=2.5,>2400 \text { to } \\
\leq 3400=1.5,>3400=0 \\
\left.\text { - alcohol intake (drinks day }{ }^{-1}\right): \leq 2=2.5,>2 \text { to } \\
\leq 3=1.5,>3 \text { to } \leq 4=1.0,>4=0 \\
\text { - added fats }\left(\mathrm{g} \mathrm{day}^{-1}\right): \leq 25=2.5,>25 \text { to } \\
\leq 50=1.5,>50 \text { to } \leq 75=1.0,>75=0 \\
\text { - } \text { servings of sugary foods (daily)§, sum (candy, cookies, } \\
\text { doughnuts, soft drinks) } / 4 \times 2.5\end{array}$ \\
\hline
\end{tabular}

* Based on 1992 Food Guide Pyramid recommendations.

† Based on 1997 dietary reference intakes - adequate intake for calcium.

$\ddagger$ Based on 2001 dietary reference intakes - recommended dietary allowance for iron.

$\S$ Changed from original DQI-R added-sugar category to a sugary foods category.

\section{Otber measurements}

At enrolment, participants also completed a detailed selfadministered questionnaire and were interviewed by trained and certified clinical staff regarding demographic characteristics, lifestyle factors, medical history, medication use, activities of daily living and a host of other items pertaining to fracture risk assessment ${ }^{13}$. Relevant to this analysis were items regarding age, race and ethnicity, marital status, education level, smoking status, physical activity, self-rated health and vitamin supplement use. Weight and height were measured at the baseline clinic visit using a standardised protocol, and body mass index (BMI) was calculated as weight in kilograms divided by the square of height in metres. Physical activity was determined using the previously validated Physical Activity Scale for the Elderly (PASE) ${ }^{19}$. We hypothesised that geographic location, age, race/ethnicity, self-perceived health and marital status would directly influence dietary intake and quality. We chose education level as a marker of socio-economic position and exposure to healthy eating messages, whereas current smoking status, physical activity, BMI and supplement use were chosen as markers of a healthy lifestyle.

\section{Data analysis}

Frequencies and means were used to describe variation in demographic factors by study site. DQI scores are presented as a continuous variable and as categories of the DQI scores. Variation in mean intake of each of the individual DQI components was analysed by DQI category. Variation in mean DQI (standard deviation (SD)) scores by each of the demographic characteristics is presented with the $P$-value for the univariate associations with diet quality. Multiple linear regression was performed to evaluate the multivariate relationships between the sociodemographic variables and DQI scores. All potential 
predictor variables that were statistically significant at a $P$-value $<0.05$ in the univariate analyses were entered into the multivariate model. Estimated total calorie intake was included in the final model in an effort to account for potential reporting error. Given the lack of a strong theoretical or biological rationale for a hierarchical entering of predictor variables into the model, we chose to use an a priori (forced) model as opposed to a stepwise model. A type I error of $<0.05$ was considered statistically significant for all tests. All statistical analyses were performed using the SAS/PC program, version 9.1 (SAS Institute, Inc.).

Of the full 5995 participants, 19 refused to complete the FFQ and 21 were excluded from the analyses due to $>10 \%$ missing data on the FFQ. An additional 27 men were excluded from the analysis data set due to implausibly low reported calorie intake $\left(<400 \mathrm{kcalday}^{-1}\right.$, no maximum caloric intake was set), leaving a final data set of 5928 participants aged 65-100 years for these analyses.

\section{Results}

As shown in Table 2, nearly half of the men were overweight (BMI $>25$ to $\leq 30 \mathrm{~kg} \mathrm{~m}^{-2}$ ), but levels of obesity $\left(\mathrm{BMI}>30 \mathrm{~kg} \mathrm{~m}^{-2}\right.$ ) varied between sites, ranging from $12 \%$ in Palo Alto to $28 \%$ in Pittsburgh. Although most MrOS participants self-identified as white, there was significant variation between sites, with Birmingham having the largest proportion of African-American men (almost 10\%). The majority of men were relatively well educated (53.2\% completed college), perceived themselves to be in good to excellent health (85.8\%), were married (82.4\%) and reported using an individual or multivitamin supplement (74.9\%); supplement use was most common in the West Coast sites.

Modified DQI-R scores were calculated for each individual. Higher scores represent a higher quality diet; out of a possible 100 points, scores ranged from 20.4 to 91.4 , with a median score of 63.1 and an overall mean (SD) DQI-R for the entire cohort of 62.5 (13.1). Table 3 shows the mean values for each component of the DQI-R by DQI-R score group, ranging from $<40$ to $>80$. The mean value of each component increased or decreased in the expected direction based on the scoring algorithm, with the exception of the diet moderation score. For example, those with a DQI-R $>80$ had the lowest intake of fats, total and saturated fat, and cholesterol, and the highest intake of fruits, vegetables, grains, calcium and iron, whereas the diet moderation score was almost the same for each group. Table 3 also shows total mean intakes for the cohort. The mean daily intake of fat was $36.5 \%$ of calories, higher than the recommended intake $(30 \%$ of calories), but mean intake of saturated fat, $11 \%$ of calories, was close to the recommended $10 \%$. The average percentage of recommended servings of fruits consumed per day was just over $70 \%$, indicating that on average the MrOS participants ate (depending upon total calorie intake),
Table 2 Frequency of baseline demographic variables in the MrOS cohort $(n=5928)$

\begin{tabular}{|c|c|}
\hline Characteristic & Percentage \\
\hline \multicolumn{2}{|l|}{ Age (years) } \\
\hline $65-69$ & 29.6 \\
\hline $70-74$ & 28.6 \\
\hline $75-79$ & 27.6 \\
\hline $80-85$ & 11.3 \\
\hline$>85$ & 3.0 \\
\hline \multicolumn{2}{|l|}{$\mathrm{BMI}\left(\mathrm{kg} \mathrm{m}^{-2}\right)$} \\
\hline$\leq 20$ & 1.0 \\
\hline$>20$ to $\leq 25$ & 26.3 \\
\hline$>25$ to $\leq 30$ & 51.3 \\
\hline$>30$ & 21.4 \\
\hline \multicolumn{2}{|l|}{ Race/ethnicity } \\
\hline White & 89.6 \\
\hline African-American & 4.0 \\
\hline Asian & 3.0 \\
\hline Hispanic & 2.1 \\
\hline Other & 1.2 \\
\hline \multicolumn{2}{|l|}{ Education (years) } \\
\hline Less than high school & 6.5 \\
\hline High school/some college & 40.3 \\
\hline College/some graduate school & 28.8 \\
\hline Graduate school & 24.4 \\
\hline \multicolumn{2}{|l|}{ Marital status } \\
\hline Married & 82.4 \\
\hline Widowed & 8.8 \\
\hline Separated/divorced & 6.1 \\
\hline Single & 2.7 \\
\hline \multicolumn{2}{|l|}{ Smoking status } \\
\hline Non-smoker & 37.4 \\
\hline Ex-smoker & 59.2 \\
\hline Current smoker & 3.4 \\
\hline \multicolumn{2}{|l|}{ Physical activity (PASE) } \\
\hline$\leq 100$ & 25.1 \\
\hline$>100 \leq 141.9$ & 25.0 \\
\hline$>141.9$ to $\leq 186$ & 25.0 \\
\hline$>186$ & 25.0 \\
\hline \multicolumn{2}{|l|}{ Self-perceived health } \\
\hline Very poor/poor/fair & 14.2 \\
\hline Good/excellent & 85.8 \\
\hline \multicolumn{2}{|l|}{ Supplement use } \\
\hline None & 21.6 \\
\hline Individual supplement & 58.7 \\
\hline Multivitamin & 16.3 \\
\hline Missing & 3.4 \\
\hline
\end{tabular}

nearly two or nearly three servings of fruit per day. On average, men ate $93.1 \%$ of the recommended $4-5$ servings of vegetables per day; but the men consumed only just over half (58\%) of the recommended 6-9 servings of grain products per day. The mean intake of calcium was approximately two-thirds of the recommended adequate intake. In contrast, on average, men consumed one and a half times the recommended dietary allowance of iron. Finally, the diets of these men were not highly diverse, with a mean diet diversity score of 3.1 out of a possible 10 . Men demonstrated some degree of moderation in their choices for discretionary items such as alcohol consumption, use of added fat or intake of sugary snacks (mean diet moderation score $=4.9$ out of a possible 10 ).

Table 3 also shows the mean intake of several other dietary components not included in the calculation of the 
Table 3 Mean intake/score for each dietary component by the modified Diet Quality Index-Revised (DQI-R) score category among 5928 men $\geq 65$ years of age

\begin{tabular}{|c|c|c|c|c|c|c|c|}
\hline & \multirow{2}{*}{$\frac{\text { Total }}{\text { Mean (SD) }}$} & \multicolumn{6}{|c|}{ Modified DQI-R score category } \\
\hline & & $\leq 40$ & $>40$ to $\leq 50$ & $>50$ to $\leq 60$ & $>60$ to $\leq 70$ & $>70$ to $\leq 80$ & $>80$ \\
\hline No. of subjects & 5928 & 292 & 823 & 1334 & 1645 & 1281 & 553 \\
\hline Energy from fat (\%) & $36.5(8.1)$ & 47.7 & 44.1 & 40.2 & 35.7 & 31.0 & 25.5 \\
\hline Energy from saturated fat (\%) & $11.0(3.0)$ & 15.5 & 14.1 & 12.4 & 10.7 & 8.8 & 7.0 \\
\hline Daily cholesterol intake (mg) & $189.7(112.3)$ & 243.4 & 243.6 & 211.1 & 179.8 & 156.9 & 134.5 \\
\hline $\begin{array}{l}\% \text { of the recommended } \\
\text { servings of fruit consumed }\end{array}$ & $70.9(40.4)$ & 44.8 & 38.4 & 55.9 & 74.1 & 94.2 & 117.5 \\
\hline $\begin{array}{l}\% \text { of the recommended servings } \\
\text { of vegetables consumed }\end{array}$ & $93.1(57.5)$ & 37.6 & 69.3 & 78.7 & 92.0 & 114.2 & 143.2 \\
\hline $\begin{array}{l}\% \text { of the recommended servings } \\
\text { of whole grains consumed }\end{array}$ & $58.7(24.7)$ & 32.9 & 45.0 & 53.4 & 59.1 & 69.2 & 79.8 \\
\hline $\begin{array}{l}\% \text { of daily recommended } \\
\text { intake - calcium }\end{array}$ & $66.7(32.1)$ & 37.6 & 54.3 & 61.4 & 66.0 & 75.0 & 96.5 \\
\hline $\begin{array}{l}\% \text { of daily recommended } \\
\text { intake - iron }\end{array}$ & $160.8(74.9)$ & 93.8 & 133.7 & 153.1 & 161.4 & 180.8 & 207.4 \\
\hline Diet diversity $(0-10)$ & $3.1(1.4)$ & 1.2 & 2.1 & 2.7 & 3.3 & 3.9 & 4.6 \\
\hline Dietary moderation $(0-10)$ & $4.9(1.0)$ & 4.7 & 4.8 & 4.8 & 4.9 & 4.9 & 4.9 \\
\hline $\begin{array}{l}\text { Total calories } \\
(\mathrm{MJ})\end{array}$ & $\begin{array}{c}1621.9(639.2) \\
(6.8)\end{array}$ & $\begin{array}{c}1259.4 \\
(5.3)\end{array}$ & $\begin{array}{c}1612.8 \\
(6.8)\end{array}$ & $\begin{array}{c}1663.3 \\
(6.8)\end{array}$ & $\begin{array}{c}1614.1 \\
(6.8)\end{array}$ & $\begin{array}{c}1646.0 \\
(6.8)\end{array}$ & $\begin{array}{c}1694.2 \\
(7.1)\end{array}$ \\
\hline Energy from carbohydrates (\%) & $50.2(8.7)$ & 37.9 & 42.0 & 46.5 & 51.1 & 56.0 & 61.2 \\
\hline Energy from protein (\%) & $16.1(2.9)$ & 16.1 & 15.9 & 15.7 & 16.0 & 16.4 & 17.1 \\
\hline Energy from sweets (\%) & $13.5(9.5)$ & 17.7 & 16.5 & 15.4 & 13.6 & 10.7 & 8.6 \\
\hline $\begin{array}{l}\text { Monounsaturated fat } \\
\text { (\% of total fat) }\end{array}$ & $38.3(3.8)$ & 37.7 & 37.4 & 37.8 & 38.6 & 38.8 & 39.4 \\
\hline $\begin{array}{l}\text { Polyunsaturated fat } \\
\text { (\% of total fat) }\end{array}$ & $25.2(5.3)$ & 21.2 & 22.3 & 23.8 & 25.3 & 27.5 & 29.4 \\
\hline
\end{tabular}

SD - standard deviation.

DQI-R. Mean caloric intake was highest among men in the highest DQI-R category. However, a larger percentage of these calories came from carbohydrates and proteins and a smaller percentage from sweets, compared with men in the lower DQI-R categories. Additionally, intake of monounsaturated and polyunsaturated fats as a percentage of total fat increased with improving DQI-R score.

In univariate analyses, variation in mean modified DQI-R was significantly associated with age, BMI, total calorie intake, education, marital status, study site, smoking status, supplement use and self-reported health status (Table 4). Modified DQI-R scores were directly related to age and education, such that men in the oldest age group ( $>80$ years old), and those with higher attained education had the highest mean DQI-R scores. As expected, DQI-R scores were inversely related to body size (higher BMI = lower DQI-R) and, with the exception of those with the very lowest caloric intake, were inversely related to total calories such that men with the highest caloric intake had a lower mean modified DQI-R score. Modified DQI-R scores were lower among separated or divorced men, and mean modified DQI-R scores for Asians and whites were higher than those of African-Americans and Hispanics. The California sites (Palo Alto (65.4) and San Diego (63.8)) had the highest mean modified DQI-R scores, while Birmingham had the lowest (59.7). Smokers had a significantly lower modified DQI-R than either never or ex-smokers.

To determine the extent to which each characteristic independently explained variation in the modified DQI-R, all variables were entered simultaneously in a multivariate model. Age, BMI, total calorie intake, education, race/ethnicity, study site, smoking status and supplement use were each independent predictors of modified DQI-R score (Table 4). Marital status, physical activity and selfperceived health status were not independent predictors of modified DQI-R in the multivariate model. The multivariate model explained $15 \%$ of the variation in modified DQI-R scores; the $P$-values associated with each characteristic are shown in Table 4. None of these characteristics showed a correlation of $>0.17$, indicating that collinearity does not preclude their being considered together in a single model.

\section{Discussion}

This cross-sectional analysis provides a description of the dietary intake and adequacy in a community-based sample of older US men. Further, these results provide some insight into sociodemographic factors that may play an important role in predicting diet quality. Our results suggest that even among a self-selected group of healthy older men, overall diet quality remains a concern, with a mean modified DQI$\mathrm{R}$ for the entire study population of 62.5 (13.1) out of an ideal of 100. In this cohort, younger age, very low total calorie intake ( $\leq 1187 \mathrm{kcal} \mathrm{day}^{-1}$ ), higher BMI, residence in a North or Southeast community, being of AfricanAmerican or Hispanic race, being less educated, not using 
Table 4 Mean modified Diet Quality Index-Revised (DQI-R) scores and regression analyses for a univariate and multivariate model by selected demographic characteristics of 5928 men $\geq 65$ years of age

\begin{tabular}{|c|c|c|c|c|c|}
\hline & $n$ & $\begin{array}{c}\text { Mean modified } \\
\text { DQI-R }\end{array}$ & SD & $\begin{array}{c}\text { Univariate } \\
P \text {-value }\end{array}$ & $\begin{array}{c}\text { Multivariable } \\
P \text {-value }\end{array}$ \\
\hline \multicolumn{6}{|l|}{ Age (years) } \\
\hline$\leq 69$ & 1752 & 60.9 & 13.6 & & \\
\hline$>69$ to $\leq 74$ & 1694 & 62.1 & 13.0 & & \\
\hline$>74$ to $\leq 80$ & 1638 & 63.5 & 12.7 & & \\
\hline$>80$ to $\leq 85$ & 667 & 64.7 & 12.3 & & \\
\hline$>80$ & 177 & 66.0 & 11.4 & $<0.0001$ & $<0.0001$ \\
\hline \multicolumn{6}{|l|}{$\mathrm{BMI}\left(\mathrm{kg} \mathrm{m}^{-2}\right)$} \\
\hline$\leq 20$ & 59 & 66.4 & 14.8 & & \\
\hline$>29$ to $\leq 25$ & 1560 & 65.7 & 13.1 & & \\
\hline$>25$ to $\leq 30$ & 3040 & 62.4 & 12.7 & & \\
\hline$>30$ & 1269 & 58.8 & 12.7 & $<0.0001$ & $<0.0001$ \\
\hline \multicolumn{6}{|l|}{ Total calories (MJ) per day } \\
\hline$>0$ to $\leq 1187 \mathrm{kcal}(>0$ to $\leq 5.0 \mathrm{MJ})$ & 1482 & 58.1 & 13.5 & & \\
\hline$>1187$ to $\leq 1529 \mathrm{kcal}(>5.0$ to $\leq 6.4 \mathrm{MJ})$ & 1482 & 65.6 & 12.5 & & \\
\hline$>1529$ to $\leq 1944 \mathrm{kcal}(>6.4$ to $\leq 8.1 \mathrm{MJ})$ & 1482 & 63.5 & 12.5 & & \\
\hline$>1944 \mathrm{kcal}(>8.1 \mathrm{MJ})$ & 1482 & 63.0 & 12.6 & $<0.0001$ & $<0.0001$ \\
\hline \multicolumn{6}{|l|}{ Education (highest year completed) } \\
\hline$\leq$ High school & 383 & 59.3 & 13.1 & & \\
\hline Some college & 2390 & 60.5 & 13.1 & & \\
\hline Some graduate school & 1709 & 63.7 & 12.8 & & \\
\hline Graduate school & 1446 & 65.5 & 12.5 & $<0.0001$ & $<0.0001$ \\
\hline \multicolumn{6}{|l|}{ Marital status } \\
\hline Married & 4886 & 62.8 & 12.9 & & \\
\hline Widowed & 524 & 61.9 & 13.1 & & \\
\hline Separated/divorced & 359 & 60.0 & 14.2 & & \\
\hline Single & 159 & 61.8 & 13.4 & 0.0004 & 0.07 \\
\hline \multicolumn{6}{|l|}{ Race/ethnicity } \\
\hline White & 5313 & 62.3 & 13.1 & & \\
\hline African-American & 238 & 56.8 & 12.2 & & \\
\hline Asian & 180 & 66.7 & 11.6 & & \\
\hline Hispanic & 127 & 61.2 & 13.3 & & \\
\hline Other & 70 & 62.1 & 13.8 & 0.48 & 0.01 \\
\hline \multicolumn{6}{|l|}{ Study site } \\
\hline Birmingham & 963 & 59.7 & 12.7 & & \\
\hline Minneapolis & 995 & 62.9 & 12.9 & & \\
\hline Palo Alto & 982 & 65.4 & 12.9 & & \\
\hline Pittsburgh & 1000 & 60.9 & 13.0 & & \\
\hline Portland & 979 & 62.5 & 12.8 & & \\
\hline San Diego & 1009 & 63.8 & 13.3 & $<0.0001$ & $<0.0001$ \\
\hline \multicolumn{6}{|l|}{ Smoking status* } \\
\hline Non-smoker & 2216 & 64.3 & 12.9 & & \\
\hline Ex-smoker & 3508 & 62.0 & 12.8 & & \\
\hline Current smoker & 203 & 52.5 & 13.1 & $<0.0001$ & $<0.0001$ \\
\hline \multicolumn{6}{|l|}{ Physical activity (PASE score)* } \\
\hline$\leq 100$ & 1484 & 62.2 & 12.9 & & \\
\hline$>100$ to $\leq 141.9$ & 1478 & 62.1 & 13.1 & & \\
\hline$>141.9$ to $\leq 186$ & 1482 & 63.1 & 12.9 & & \\
\hline$>186$ & 1481 & 62.7 & 13.4 & 0.12 & 0.12 \\
\hline \multicolumn{6}{|l|}{ Supplement use } \\
\hline Non-users & 1282 & 58.7 & 12.9 & & \\
\hline Individual vitamins & 3477 & 63.8 & 12.9 & & \\
\hline Multivitamins & 969 & 63.4 & 12.7 & & \\
\hline & 200 & 60.9 & 13.9 & $<0.0001$ & $<0.0001$ \\
\hline \multicolumn{6}{|l|}{ Self-reported health status* } \\
\hline Very poor/poor/fair & 843 & 61.4 & 12.7 & & \\
\hline Good/excellent & 5083 & 62.7 & 13.1 & 0.005 & 0.82 \\
\hline
\end{tabular}

BMI - body mass index; PASE - Physical Activity Scale for the Elderly.

*Data were missing for one individual for smoking, three individuals for physical activity and two for self-reported health status.

dietary supplements and smoking were each significant independent predictors of a poorer diet.

Other researchers have reported the diet quality of a particular population using the DQI or other similar index of diet quality ${ }^{8,9,20}$, but few have considered the potential association between diet quality and sociodemographic characteristics $^{12,21-23}$. In a survey-based study of 460 Quebecers aged 55-74 (47\% male), fewer than half of the men were considered to have adequate diet diversity, suggesting lower than recommended intake of several 
food groups ${ }^{24}$. In a later paper, this group reported that eating breakfast, consumption of prepared meals and social support were positive predictors of diet diversity ${ }^{6}$. Two or fewer meals per day and smoking were predictors of a lower diet adequacy score. Use of nutrient supplements was a significant predictor of both poor diet diversity and poor diet adequacy. Our data support the negative association between smoking and diet quality, but show a positive association between any supplement use and diet quality. Thus, it appears that supplements in the Quebec population may have been used to improve poor diet, while in the US cohort, supplement use may reflect greater health consciousness. We did not assess the number of meals per day.

A similar assessment of diet quality and predictors of diet quality was performed using household survey data from 1085 adults in Botswana aged 60 years and older. Similar to the MrOS results, older adults in Botswana had significantly higher food variety scores if they were married, more educated and reported good health. However, the oldest adults in the Botswana population ( $\geq 80$ years) reported a significantly poorer food variety score than younger subjects, while in the MrOS population age was directly related to diet quality, with the oldest men ( $\geq 80$ years) having the highest mean modified DQI-R score. In a British population, Pryer et al. used cluster analysis to identify four eating patterns in 1197 men and women $^{22}$. Although these results from a cluster analysis are not directly comparable with those from the DQI, there were some similar findings among men in the 'healthier diet' cluster and men with a higher DQI-R score. Specifically, among the 1087 men surveyed, significantly higher proportions of men in the 'healthier diet' cluster (characterised by higher intake of whole grains, fish and shellfish, and fruits/ nuts) were from non-manual social classes and were non-smokers.

While few studies have investigated variations in diet quality by geographic location within the USA, HavemanNies et al. reported on differences in diet quality, as assessed using three different measures, in two European cohorts and one from the USA (Framingham) ${ }^{10}$. Diet quality differed by geographic location, with individuals from Framingham in the northern USA and individuals from Southern Europe having a diet profile high in complex carbohydrate and low in saturated fat, while individuals from Northern Europe were characterised by a dietary profile low in complex carbohydrate and high in saturated fat. Interestingly, these differences are not dissimilar from the diet quality differences we report between Eastern and Western sites in MrOS.

Finally, to investigate how education (as a marker for socio-economic status) may modify the effect of the other demographic variables, we stratified our analyses by education. With the exception of BMI, the direction and magnitude of the associations between each demographic variable and DQI score remained the same within each quartile of education. However, as shown in Fig. 1, among men with the lowest BMI, the relationship between BMI and DQI in the lowest categories of education differs from those with higher levels of education. This may reflect different reasons for the lower BMI, with the men with the lowest education having a lower BMI due to issues of inadequate access to food, while men with higher education have a lower BMI due to better food choices. While others have reported a similar independent association between education and diet quality and BMI and diet quality ${ }^{22,25}$, we are not aware of any analyses that have reported the variations in this association with stratification. However, these results must be viewed cautiously as the number of men in our lowest BMI category is small $(n=59)$.

To our knowledge, this is one of a handful of studies of diet quality in older adults that have been able to address the potential effect of race or ethnicity and geographic region of residence effectively, and the only one that measured dietary intake in all geographic regions during the same time period with the same assessment instrument. Ethnicity, as a marker of cultural beliefs and heredity, is commonly suggested as a predictor of dietary intake. In our univariate analyses, ethnic origin was not a significant predictor of diet quality. However, when adjusted for geographic location (site) and other characteristics in the multivariate model, race/ethnicity became a significant predictor, with Asian-Americans having the highest modified DQI-R score and AfricanAmericans the lowest. It must be noted though, that the small number of MrOS participants in non-Caucasian ethnic groups is likely to have limited our ability to identify small but potentially important associations.

Another limitation of this study may be the modified DQI-R itself. We chose to modify an existing diet index for application to our particular population. While a strength of this decision is that the predictive properties of the DQI-R have been well described, there are several concerns. First, this tool was not developed specifically for elderly men; rather it was developed to reflect dietary guidelines for the general US population. Secondly, the DQI-R was developed using two 24-hour recalls, while our dietary assessment method was an FFQ, leading to the need to modify the calculation of the dietary moderation scale. Because our FFQ did not include some of the specific diet moderation items, e.g. use of added sugar, it was necessary to impute new values for these behaviours based on actual intake. This imputation may explain the rather low and 'invariable' dietary moderation scores in our population. However, Newby et al. ${ }^{8}$ recently evaluated the reliability and validity of the DQI-R as assessed using an FFQ, and reported that DQI-R scores determined using an FFQ correlated well with those produced using a diet record, and the DQI-R scores from the FFQ were significantly correlated with several biomarkers of nutrient intake, supporting the FFQ-based DQI-R as a valid assessment of intake ${ }^{8}$. An advantage of the DQI-R is that the components 


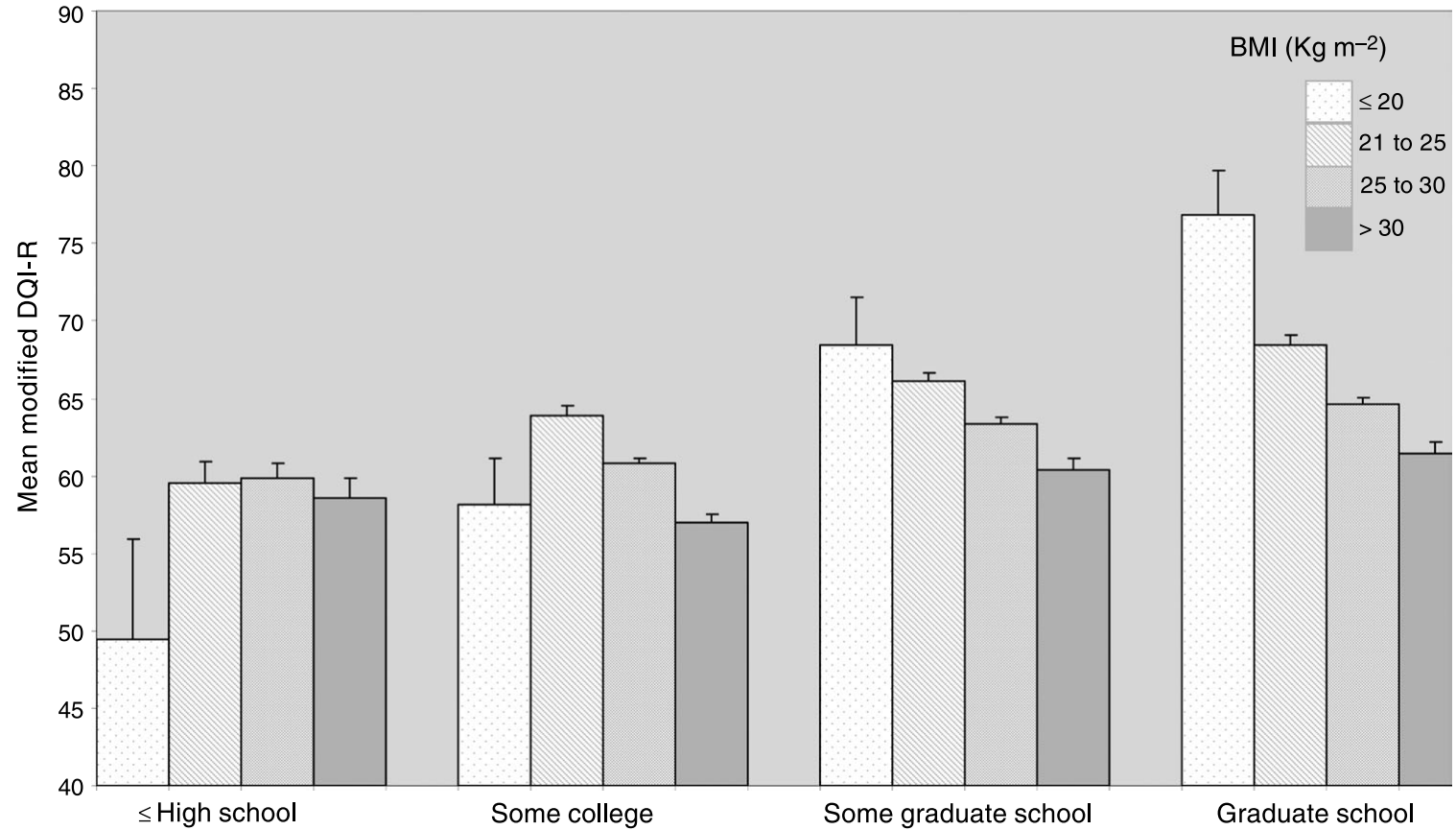

Fig. 1 Variations in mean modified Diet Quality Index-Revised (DQI-R) by body mass index (BMI), stratified by education, in 5928 men aged $\geq 65$ years

are easily understood by the general population, and reflected the 1992 Food Guide Pyramid.

The assessment of diet quality is directly influenced by the limitations of the initial dietary assessment tool. Dietary intake in the MrOS population was assessed using a relatively short FFQ, thus, we may be underestimating diet diversity, particularly among men who consume ethnic or less common foods. One effect of this underestimation may be a skewing of the diet diversity score to the left, as is seen in Table 3, where even among the men with a modified DQI-R of $\geq 80$, the mean diet diversity score was 5.0 out of a possible 10 points.

The primary goal of this analysis was to provide information about the need for interventions to improve poor diets, and to define the target population characteristics. Because this is a cross-sectional study, we cannot assess the temporality between the DQI and disease. Associations between the DQI-R score and disease outcomes have been studied by two groups, with inconclusive results $^{9,26}$. Others have associated disease risk with other markers of diet quality such as the Health Eating Index ${ }^{27-29}$. We plan to study diet-disease association when the MrOS cohort has been followed for longer.

\section{Conclusion and application}

In the USA, as in most of the world, the proportion of the population aged $\geq 65$ years is increasing. With ageing, individuals are at increased risk of developing chronic diseases commonly associated with poor quality or excess quantity diets. Yet, targeting dietary interventions to a particular group at greatest risk is difficult, as the presence of many of these factors is not easily determined at a population level. In the analyses presented, we chose several easily obtained characteristics that could be used to target interventions toward particular groups who appear to have particularly poor diet quality. Our results suggesting that there is a nearly $40 \%$ prevalence of poor diet even in selfselected healthy volunteers could provide some guidance on characteristics that identify men at high risk.

\section{Acknowledgements}

The Osteoporotic Fractures in Men (MrOS) study is supported by National Institutes of Health funding. The following institutes provide support: the National Institute of Arthritis and Musculoskeletal and Skin Diseases (NIAMS), the National Institute on Aging (NIA) and the National Cancer Institute (NCI), under the following grant numbers: U01 AR45580, U01 AR45614, U01 AR45632, U01 AR45647, U01 AR45654, U01 AR45583, U01 AG18197 and M01 RR000334

\section{References}

1 Anderson JJ, Suchindran CM, Kritchevsky SB, Barrett-Connor E. Macronutrient intakes of elderly in the Lipid Research Clinics Program Prevalence Study. Journal of Nutritional Health and Aging 2004; 8: 395-9.

2 Hartman AM, Brown CC, Palmgren J, Pietinen P, Verkasalo M, Myer D, et al. Variability in nutrient and food intakes among older middle-aged men. Implications for design of 
epidemiologic and validation studies using food recording. American Journal of Epidemiology 1990; 132: 999-1012.

3 Murphy SP, Rose D, Hudes M, Viteri FE. Demographic and economic factors associated with dietary quality for adults in the 1987-88 Nationwide Food Consumption Survey. Journal of the American Dietetic Association 1992; 92 : $1352-7$.

4 Ganji V, Betts N. Fat, cholesterol, fiber and sodium intakes of US population: evaluation of diets reported in 1987-88 Nationwide Food Consumption Survey. European Journal of Clinical Nutrition 1995; 49: 915-20.

5 Radimer K, Bindewald B, Hughes J, Ervin B, Swanson C, Picciano MF. Dietary supplement use by US adults: data from the National Health and Nutrition Examination Survey, 19992000. American Journal of Epidemiology 2004; 160: 339-49.

6 Drewnowski A, Henderson SA, Driscoll A, Rolls BJ. The Dietary Variety Score: assessing diet quality in healthy young and older adults. Journal of the American Dietetic Association 1997; 97: 266-71.

7 Drewnowski A, Henderson SA, Shore AB, Fischler C, Preziosi P, Hercberg S. Diet quality and dietary diversity in France: implications for the French paradox. Journal of the American Dietetic Association 1996; 96: 663-9.

8 Newby PK, Hu FB, Rimm EB, Smith-Warner SA, Feskanich D, Sampson L, et al. Reproducibility and validity of the Diet Quality Index Revised as assessed by use of a foodfrequency questionnaire. American Journal of Clinical Nutrition 2003; 78: 941-9.

9 Seymour JD, Calle EE, Flagg EW, Coates RJ, Ford ES, Thun MJ. Diet Quality Index as a predictor of short-term mortality in the American Cancer Society Cancer Prevention Study II Nutrition Cohort. American Journal of Epidemiology 2003; 157: $980-8$

10 Haveman-Nies A, Tucker KL, de Groot LC, Wilson PW, van Staveren WA. Evaluation of dietary quality in relation to nutritional and lifestyle factors in elderly people of the US Framingham Heart Study and the European SENECA study. European Journal of Clinical Nutrition 2001; 55: 870-80.

11 Shatenstein B, Nadon S, Ferland G. Diet quality among older Quebecers as assessed by simple indicators. Canadian Journal of Dietetic Practice and Research 2003; 64: 174-80.

12 Ledikwe JH, Smiciklas-Wright H, Mitchell DC, Miller CK, Jensen GL. Dietary patterns of rural older adults are associated with weight and nutritional status. Journal of the American Geriatrics Society 2004; 52: 589-95.

13 Orwoll E, Blank JB, Barrett-Connor E, Cauley J, Cummings S, Ensrud $\mathrm{K}$, et al. Design and baseline characteristics of the osteoporotic fractures in men (MrOS) study - a large observational study of the determinants of fracture in older men. Contemporary Clinical Trials 2005; 26: 569-85.

14 Block G, Hartman AM, Naughton D. A reduced dietary questionnaire: development and validation. Epidemiology 1990; 1: 58-64.

15 Haines PS, Siega-Riz AM, Popkin BM. The Diet Quality Index revised: a measurement instrument for populations. Journal of the American Dietetic Association 1999; 99: 697-704.
16 Patterson RE, Haines PS, Popkin BM. Diet quality index: capturing a multidimensional behavior. Journal of the American Dietetic Association 1994; 94: 57-64.

17 Standing Committee on the Scientific Evaluation of Dietary Reference Intakes. DRI Dietary Reference Intakes for Calcium, Phosphorus, Magnesium, Vitamin D, and Fluoride. Washington, DC: National Academy Press, 1997.

18 Panel on Micronutrients Standing Committee on the Scientific Evaluation of Dietary Reference Intakes, Food and Nutrition Board. Dietary Reference Intakes for Vitamin A, Vitamin K, Arsenic, Boron, Chromium, Copper, Iodine, Iron, Manganese, Molybdenum, Nickel, Silicon, Vanadium, and Zinc. Washington, DC: National Academy Press, 2001.

19 Washburn RA, McAuley E, Katula J, Mihalko SL, Boileau RA. The physical activity scale for the elderly (PASE): evidence for validity. Journal of Clinical Epidemiology 1999; 52: 643-51.

20 Pennington JA, Schoen SA. Total diet study: estimated dietary intakes of nutritional elements, 1982-1991. International Journal for Vitamin and Nutrition Research 1996; 66: 350-62.

21 Davis MA, Murphy SP, Neuhaus JM, Lein D. Living arrangements and dietary quality of older U.S. adults. Journal of the American Dietetic Association 1990; 90: 1667-72.

22 Pryer JA, Nichols R, Elliott P, Thakrar B, Brunner E, Marmot M. Dietary patterns among a national random sample of British adults. Journal of Epidemiology and Community Health 2001; 55: 29-37.

23 Clausen T, Charlton KE, Gobotswang KS, Holmboe-Ottesen G. Predictors of food variety and dietary diversity among older persons in Botswana. Nutrition 2005; 21: 86-95.

24 Shatenstein B, Nadon S, Ferland G. Determinants of diet quality among Quebecers aged 55-74. Journal of Nutritional Health and Aging 2004; 8(2): 83-91.

25 Reedy J, Haines PS, Campbell MK. The influence of health behavior clusters on dietary change. Preventive Medicine 2005; 41: 268.

26 Fung TT, McCullough ML, Newby PK, Manson JE, Meigs JB, Rifai N, et al. Diet-quality scores and plasma concentrations of markers of inflammation and endothelial dysfunction. American Journal of Clinical Nutrition 2005; 82: 163-73.

27 McCullough ML, Feskanich D, Rimm EB, Giovannucci EL, Ascherio A, Variyam JN, et al. Adherence to the Dietary Guidelines for Americans and risk of major chronic disease in men. American Journal of Clinical Nutrition 2000; 72 : 1223-31.

28 McCullough ML, Feskanich D, Stampfer MJ, Giovannucci EL, Rimm EB, Hu FB, et al. Diet quality and major chronic disease risk in men and women: moving toward improved dietary guidance. American Journal of Clinical Nutrition 2002; 76: 1261-71.

29 McCullough ML, Feskanich D, Stampfer MJ, Rosner BA, Hu FB, Hunter DJ, et al. Adherence to the Dietary Guidelines for Americans and risk of major chronic disease in women. American Journal of Clinical Nutrition 2000; 72: 1214-22. 